\title{
Statistical Design and Analysis of Intercropping Experiments
}

\author{
by \\ Walter T. Federer \\ Department of Plant Breeding and Biometry \\ Cornell University
}

BU-1115-MA*

February 1991

\begin{abstract}
Treatment design and plot technique for intercropping experiments are different than for sole cropping experiments. The experiment design does not depend upon the nature of the treatments. The statistical analysis depends heavily upon the nature, type, and make-up of the treatment design. As a result, quite different statistical analyses are used for intercropping as compared to sole cropping experiments. There are many more aspects for intercropping experiments. Some of these are land use, economic, nutritional, multivariate, soil erosion and structure, pests, and biological. Each of these aspects is briefly discussed.
\end{abstract}

*In the Technical Report Series of the Biometrics Unit, Cornell University, Ithaca, NY 14853. 


\section{INTRODUCTION}

The terms intercropping, multiple cropping, and polycropping are considered synonymous for the purposes of this paper (see, e.g., Kass, 1978, for details). Statistical design covers the many aspects of planning and designing experiments (see, e.g., Federer, 1984). Three particular aspects of statistical design are addressed in this paper, i.e., treatment design, experiment design, and experimental unit technique with most of the emphasis being placed upon statistical analyses for the various experiment and treatment designs.

Experiment design, the arrangement of treatments (entities of interest) in an experiment, for intercropping experiments does not depend upon whether or not the experiment involves mixtures of crops or lines or only sole or single crop treatments. The selection of an experiment design depends upon the type and nature of experimental variation in the place where the experiment is to be conducted. Blocking and confounding considerations and not types of treatment are the factors determining which experiment design is selected for the experiment.

Treatment design, the selection of entities to be included in an experiment, is crucially connected with the type of statistical analysis appropriate for an experiment. The nature and type of statistical analysis is, or should be, determined by the treatment design. It should not then be a surprise to find that statistical analyses for intercropping experiments may be, and usually are, vastly different from those used for sole cropping. Also, rather than performing a single statistical analysis for a characteristic as is usually done for a sole cropping experiment, several varied analyses will be necessary to illicit the information from data obtained from an intercropping experiment. Each intercropping experiment usually is approached from several different angles. The following represent some aspects of interest to an experimenter:

(i) land utilization (agronomic) aspect,

(ii) economic or other value aspect,

(iii) nutritional aspect,

(iv) multivariate analysis aspect, 
(v) soil erosion and structure aspect,

(vi) density and intimacy aspects,

(vii) biological modeling aspects, and

(viii) sustainability of cultivar yields to meet population needs.

From the above, the multiple scientific and practical aspects of an intercropping experiment are apparent. Each of the above aspects will be briefly discussed in the following sections. Statistical procedures associated with each aspect are discussed.

\section{EXPERIMENT DESIGN}

In planning and designing experiments, the five axioms presented by Federer (1984) should be followed in evaluating the performance of lines from a plant breeding program or entities from other programs. The choice of an experiment design, a plan for the arrangement of treatments in an experiment, is crucial in controlling experimental heterogeneity among the experimental units, the smallest unit to which one treatment is applied. There are many principles for experiment designs (see Federer, 1984) but three of the chief ones for an experimenter are randomization, blocking or stratification, and confounding. Randomization assures fairness (unbiasedness) to treatment comparisons and in estimation of an error mean square; grouping or blocking allows control or elimination of heterogeneity among experimental units (eus) by grouping like eus and minimizing variation among eus within a group and by maximizing differences among groups (blocks or strata). Partial confounding of treatment comparisons allows use of smaller blocks which may be necessary to control experimental variation.

Complete block or incomplete block designs may be used. From the published literature on intercropping experiments, most are designed as randomized complete block designs and a relatively small number as completely randomized, split plot, or split split plot designs. From a cursory review of the literature, the blocking did not control as much of the variation as it should, resulting in fairly high coefficients of variation and error mean squares. Using smaller blocks and row-column designs, 
measuring a related covariate, or using some form of nearest - neighbor analysis may control much of the extraneous experimental variation in experiments.

Incomplete block designs are often useful in blocking for and controlling experimental variation. A very large number of tabled complete block designs are available. However, these do meet all needs of experimenters. Incomplete block designs may be easily constructed for most situations encountered by experimenters. Two construction methods for use by experimenters are the ones presented in Patterson and Williams (1976) and Khare and Federer (1981). When the number of incomplete blocks equals the number of treatments, Federer (1991) presents another procedure for constructing incomplete block designs; the method is also useful for constructing row-column designs.

The shape of the experimental unit may be altered in some cases to reduce variation within a block. Long narrow plots running perpendicular to variation gradients is one method for reducing variation among eus within a block. Competition between treatments in adjacent eus should be eliminated. This can be done by increasing space between eus or by planting guard rows around eus. The latter increases the size of an experiment. Assuming that competition does not exist may be very misleading. It is suspected that most field experiments reported in published literature and which have small eus, have some element of inter-experimental unit competition. Ignoring this fact may lead to incorrect conclusions from an experiment. Statistical analyses presented in statistical methods text books assume independence among eus. The experimenter should verify whether the assumptions used for a statistical analysis are true or not. Using statistical analyses without considering their assumptions can lead to incorrect conclusions.

\section{TREATMENT DESIGN}

The treatment design, selection of treatments to be included in an experiment, is an extremely crucial item for meeting the goals of an experiment. Exclusion of required treatments can lead to loss of information on certain goals of an experiment. Likewise, the inclusion of unnecessary treatments is a waste of space, material, and an experimenter's time. Controls or standards are necessary treatments 
for inclusion in an experiment in order to have a point of reference for comparison. For intercropping experiments, the control may be a sole crop and/or it may be the standard intercrop mixture for an area. For plant breeding experiments under intercropping, the selection of the cultivars of an intercrop is an important item in evaluating breeding material for intercropping systems. In some maize breeding experiments, a single bean cultivar is often used as the other crop. If maize cultivars are to be grown with several bean cultivars in practice, a composite of the bean cultivars in the proportions they are to be grown with maize, may be used to form the intercrop under which all maize lines are evaluated.

In general, any mixture of crops may qualify as a treatment for inclusion in an intercrop experiment. For certain goals and analyses, it is necessary to include sole crops as well as all possible combinations of mixtures. For several crops, several numbers of crops in a mixture, several densities of the various crops, and other variables, the number of possible combinations becomes very large. Hence, an experimenter should choose the mixtures for inclusion in an experiment with great care. The goals of an experiment should be precisely defined, and then the treatments are selected which will allow fulfillment of the goals. If a goal is to compare a group of mixtures with a standard mixture and if the standard mixture is not included in the experiment, these comparisons will be impossible.

In selecting a treatment design, the experimenter should

(i) precisely define his goals,

(ii) select the treatments allowing accomplishment of goals,

(iii) study the proposal statistical analyses,

(iv) decide in light of (i), (ii), and (iii) if the comparisons required are possible, and

(v) revise (i), (ii), and/or (iii) if (iv) is not answered in the affirmative.

Quite often it is possible to combine a number of proposed experiments and to increase greatly the information obtained over separate experiments. Not only is more information usually obtained, but less experimental material and space may be required than for the separate experiments. For 
example, in a varietal test, an agronomist and an entomologist may want information on the same set of varieties and rather than setting up two separate experiments, one experiment would suffice. As another example, instead of setting up two experiments to investigate various levels of two different factors, a factorial arrangement in one experiment could be performed.

\section{LAND UTILIZATION (AGRONOMIC) ASPECT.}

Probably the most used method for combining the results from an intercropping experiment is to use one form of a land equivalent ratio (LER) (see Willey and Osiru, 1972.) or relative yield (see deWit and van den Bergh, 1965.). An LER is defined to be

$$
\mathrm{LER}=\sum_{\mathrm{i}=1}^{\mathrm{c}} \mathrm{Y}_{\mathrm{mi}} / \mathrm{Y}_{\mathrm{si}}
$$

where $\mathrm{Y}_{\mathrm{mi}}$ equals yield of ith crop when in a mixture, $\mathrm{Y}_{\mathrm{si}}$ equals yield of ith crop when grown as a sole crop, and c equals number of crops in a mixture. An LER as given above is poorly defined since it is not specified if $\mathrm{Y}_{\mathrm{mi}}$ are individual plot yields or are means from $\mathrm{r}$ replicates of the ith crop from a given mixture. Likewise, $\mathrm{Y}_{\mathrm{si}}$ could be obtained from a variety of sources, such as, e.g.,

(i) individual plot yields of crops as a sole crop,

(ii) mean yield from $\mathbf{r}$ replicates of sole crops $\mathbf{i}$,

(iii) some theoretical "Optimal" value for $\mathrm{Y}_{\mathrm{si}}$,

(iv) farmers yields averaged over y years, or

(v) other.

Using all of the above, ten forms of an LER could be obtained. There could be others; hence, it is absolutely necessary for an investigator to describe completely which LER has been selected for statistical analyses in order that others may comprehend the meaning of results from an experiment.

If the denominators in the ratios of an LER are random variables, the statistical distribution of the LER statistics is unknown or not usable. For example, for normal random variates $\mathrm{Y}_{\mathrm{mi}}$ and $\mathrm{Y}_{\text {si' }}$ the distribution of the ratio $\mathrm{Y}_{\mathrm{mi}} / \mathrm{Y}_{\mathrm{si}}$ is a Cauchy distribution with infinite moments, i.e., the parameters for the mean and variance of the variable $\mathrm{Y}_{\mathrm{mi}} / \mathrm{Y}_{\mathrm{si}}$ are not defined (infinite) (See Federer 
and Schwager, 1982). Since one ratio gives trouble, the sum of ratios, as in (1), is worse.

A normal variate ranges from minus infinity to plus infinity. Therefore, such characters as yield

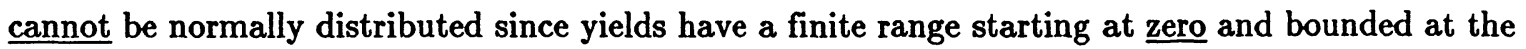
upper end. If yields are gamma or log normal distributed variates, then there is some hope for obtaining the statistical distribution of ratios and sums of ratios.

The following is one way out of the above dilemma. First, we select a base sole crop yield, say $\mathrm{Y}_{\mathrm{si}}$. We then rewrite the LER, equation (1), as a RLER as follows:

$$
\mathrm{RLER}=\sum_{\mathrm{i}=1}^{\mathrm{c}}\left(\mathrm{Y}_{\mathrm{s} 1} / \mathrm{Y}_{\mathrm{si}}\right) \mathrm{Y}_{\mathrm{mi}}=\sum_{\mathrm{i}=1}^{\mathrm{c}} \mathrm{R}_{\mathrm{i}} \mathrm{Y}_{\mathrm{mi}}
$$

where $R_{i}=Y_{s 1} / Y_{s i}$. Secondly, the ratios of yields $R_{i}$, are much more stable than are the $1 / Y_{s i}$ values; thirdly, we take the $R_{i}$ as known constants. For example, from farmers' yields over many years in an area, it might be known that maize produces five times more kilograms per hectare than does beans. For $Y_{s 1}$ equal to maize sole crop yield and $R_{b}=Y_{S}$ maize $/ Y_{S}$ beans $=5$, then for a maizebean mixture $R L E R=Y_{m}$ maize $+R_{b} Y_{m}$ beans $=Y_{m}$ maize $+5 Y_{m}$ beans.

If the denominators, $\mathrm{Y}_{\mathbf{s i}}$, in (1) or the ratios $\mathrm{R}_{\mathrm{i}}$ in (2) are constants, and if the $\mathrm{Y}_{\mathrm{mi}}$ have a multivariate normal distribution, then the LER and the RLER have a normal distribution. Ratios of yields are more stable than actual yields, and hence using them as constants is more appropriate. It should be noted that the use of RLERs and of the $R_{i}$ as constants affects the treatment design in that sole crop plots are no longer required. This is an important consequence, since reducing the size of the treatment design is an important item for most agricultural research projects.

The ratio $\mathrm{Y}_{\mathrm{mi}} / \mathrm{Y}_{\mathrm{si}}$ indicates the relative yield of crop $\mathrm{i}$ in a mixture to crop $\mathrm{i}$ grown as a sole crop. If $\mathrm{Y}_{\mathrm{mi}} / \mathrm{Y}_{\mathrm{si}}=1 / 2$ for all $\mathrm{i}$, then there would be no advantage or disadvantage to using a mixture of crops over using sole crops. When none of the $\mathrm{Y}_{\mathrm{mi}} / \mathrm{Y}_{\mathrm{si}}$ are less than 0.5 and some are larger, there would be an advantage to growing a mixture of crops. For some crop mixtures and specific varieties, one of the important crops, say $i=1$, may have $\mathrm{Y}_{\mathrm{m} 1} / \mathrm{Y}_{\mathrm{s} 1}=1$. In such cases, any value of the other $\mathrm{Y}_{\mathrm{mi}} / \mathrm{Y}_{\mathrm{si}}$ would result in an advantage for intercropping over sole cropping. In some cases, it has been 
observed that $\mathrm{Y}_{\mathrm{m} 1} / \mathrm{Y}_{\mathrm{s} 1}>1$, which makes an intercrop even more advantageous. All of the above indicates that considerable care needs to be applied in selecting an intercrop mixture. The crops, the number of crops, the particular lines or varieties of a crop, the density and intimacy of crops, and relative importance of each element of the mixture are all considerations for selection of an intercrop mixture. The LER concept is further discussed in Willey (1979).

\section{ECONOMIC OR OTHER VALUE ASPECT}

Various values may be assigned to the yield of crops in a mixture. For many people, value means monetary. For other people, value is related to how well a crop satisfies the dietary goals of a family. For still others, value may be frequency of produce for sale or barter throughout the year. Whatever value system is used, consider the value of a crop $i$ to be $P_{i}$ per unit such as a kilogram or a fruit (e.g., melon). The value of crop $i$ then will be $P_{i} Y_{i}$ where $Y_{i}$ is total yield of crop $i$ per eu in kilograms, or it could be number of fruit per eu. Since economic values may fluctuate considerably from year to year, we recommend use of a ratio of price of crop $i$ to a base crop say 1 whenever all crop values are for the same unit, say kilogram. In a mixture of crops, a linear combination of crop yields is the variable of interest to a grower. The following equations are similar to (1) and (2):

$$
\text { Crop value }=\mathrm{V}=\sum_{\mathrm{i}=1}^{\mathrm{c}} \mathrm{P}_{\mathrm{i}} \mathrm{Y}_{\mathrm{mi}} \text {, }
$$

where $\mathrm{Y}_{\mathrm{mi}}$ is the yield of crop $\mathrm{i}$ in a c crop mixture and $\mathrm{P}_{\mathrm{i}}$ is the price or value of a unit, say a kilogram or individual fruit of crop i. For relative value and ratio of values to a base value, the equation is

$$
\mathrm{RV}=\sum_{\mathrm{i}=1}^{\mathrm{c}}\left(\mathrm{P}_{\mathrm{i}} / \mathrm{P}_{1}\right) \mathrm{Y}_{\mathrm{mi}}=\sum_{\mathrm{i}=1}^{\mathrm{c}} \mathrm{R}_{\mathrm{i}} \mathrm{Y}_{\mathrm{mi}}
$$

$\mathrm{RV}$ values are recommended for use in summarizing information from an experiment.

\section{NUTRITIONAL ASPECT}

In subsistence farming areas of the world, the number of calories is of vital importance. The protein content is also of importance in order to have a proper diet for a family. Therefore, in an intercrop experiment, it is necessary to determine the total calory and/or protein content of a mixture 
in order to determine if it is more advantageous for a farmer to grow sole crops or intercrops. For example, suppose a farmer who derives his food from his farm, needs a diet composed of four grams of carbohydrates to one of protein; suppose his maize variety produces nine grams of carbohydrate to one of protein and his bean variety produces one gram of carbohydrate to one gram of protein; suppose maize produces five times more kilograms per hectare than does beans. If he grows one hectare of maize to eight hectares of beans, his total produce will have approximately four grams of carbohydrates to one gram of protein. If his total carbohydrate requirement cannot be satisfied because the farm land is not available to him, he may need to grow more maize and have a protein deficient diet. He could also grow a mixture of maize and beans in combination with one of the sole crops.

A linear programming approach (see Chapter 9 of Federer, 1991 and discussion by B.R. Trenbath in Mead and Riley, 1981) may be used when the total carbohydrate and protein requirements are stated. The optimum number of hectares of each sole crop required to attain the goal is obtained. Likewise, a linear programming approach may be used to determine the optimum distribution of acreage to achieve the stated goal using a combination of a sole crop and an intercrop.

For comparative purposes, the calory conversion factor for a particular cultivar is known or can be obtained. Then the yield of crops in a c crop mixture may be converted to calories as follows:

$$
\mathrm{C}=\sum_{\mathrm{i}=1}^{\mathrm{c}} \mathrm{C}_{\mathrm{i}} \mathrm{Y}_{\mathrm{mi}}
$$

where $\mathrm{C}_{\mathrm{i}}$ is a calory conversion factor for crop $\mathrm{i}$ The same formula may be used to obtain total protein for the mixture. As before a relative total calory (or protein) may be obtained as

$$
\mathrm{RC}=\sum_{\mathrm{i}=1}^{\mathrm{c}} \mathrm{C}_{\mathrm{i}} \mathrm{Y}_{\mathrm{mi}} / \mathrm{C}_{1}=\sum_{\mathrm{i}=1}^{\mathrm{c}} \mathrm{R}_{\mathrm{i}} \mathrm{Y}_{\mathrm{mi}}
$$

where crop one was selected as the base crop and $R_{i}=c_{i} / c_{1}$. The only reason for using $R C$ instead of $\mathrm{C}$ is for presentation purposes along with RLER and RV. The same graph may be used for all relative measurements. For interpretation purposes, formula (5) would be used.

Note that the $\mathrm{C}_{\mathrm{i}} \mathrm{Y}_{\mathrm{mi}}$ in equations (5) and (6) could be of a complex form in that carbohydrates, protein, fiber, etc. may be obtained for each crop in a mixture. The relative worths of protein to 
carbohydrate, fiber to carbohydrate, etc. may be available. A particular nutritional value for crop i would be

$$
\mathrm{C}_{\mathrm{i}} \mathrm{Y}_{\mathrm{mi}}=\left(\mathrm{C}_{\mathrm{ci}}+\mathrm{R}_{\mathrm{p} / \mathrm{c}} \mathrm{C}_{\mathrm{pi}}+\mathrm{R}_{\mathrm{f} / \mathrm{c}} \mathrm{C}_{\mathrm{fi}}+\cdots\right) \mathrm{Y}_{\mathrm{mi}}
$$

where $\mathrm{C}_{\mathrm{ci}}, \mathrm{C}_{\mathrm{pi}}, \mathrm{C}_{\mathrm{fi}}$, etc. are the conversion factors for carbohydrate, protein, fiber, etc. for crop $\mathrm{i}$ and $R_{p / c}, R_{f / c}$, etc. are the relative worths or values for protein, fiber, etc. to carbohydrate. The above would combine all nutritional measurements into a single number for each crop in a mixture

\section{MULTIVARIATE ANALYSIS}

It has sometimes been recommended that the crops of a mixture of $c$ crops be used as variates in a multivariate analysis and that a discriminant function analysis be used. As Federer and Murty (1987) demonstrate, this procedure leads to no usable information for an intercrop experimenter and is too restrictive. The mathematical criterion used to obtain a canonical variate (linear combination of yields) is to select the $a_{i}$ in

$$
\text { first canonical variate }=\sum_{i=1}^{c} a_{i} Y_{m i}
$$

in such a way that no other selection of the $a_{i}$ results in a larger ratio of treatment sum of squares divided by treatment plus error sums of squares for the first canonical variate. Then to the residuals, the above criterion is applied again to obtain a second canonical variate, say,

$$
\text { second canonical variate }=\sum_{\mathrm{i}=1}^{\mathrm{c}} \mathrm{b}_{\mathrm{i}} \mathrm{Y}_{\mathrm{mi}} .
$$

The procedure is continued until c canonical variates are obtained. As Federer and Murty (1987) point out, the $a_{i}, b_{i}$, etc., have no practical interpretation and hence are not useful for the experimenter.

Sections 4 and 5 represent other types of multivariate analyses. Likewise, the multivariate procedure put forth by Pearce and Gilliver $(1978,1979)$ may be used to summarize information from an intercropping experiment. These multivariate methods are not limited to keeping the number of crops per mixture constant as is a discriminant analysis. The Pearce and Gilliver $(1978,1979)$ procedures is given for $c=2$ but could be extended to consider $c=3$ crops in a mixture. For LER, V, and $\mathrm{C}$, the number of crops in a mixture may vary. 


\section{SOIL EROSION AND STRUCTURE ASPECT}

Sustainablility of yields over long periods of time of a farming system is highly dependent upon maintaining soil structure and reducing or eliminating soil erosion. Hence in a breeding program, it is important to evaluate lines for their performance relative to these characteristics and to select an intercropping system which maintains soil structure and controls erosion even if a line as a sole would not. This demonstrates the complexity of evaluating farming systems to obtain sustainablity.

One goal of an intercropping experiment may be to assess the amount of soil erosion and the changes in soil chemical, structural, and physical properties. For example, it is known that erosion in sole crop cassava may be high whereas erosion is drastically reduced when cassava is intercropped with melons, cowpea, or other crops (Aina et al., 1977; Lal, 1989). Likewise, in some intercrop mixtures on the same eu for two and more successive years, the earthworm activity was significantly higher than in sole crop cassava (Ezumah and Hulugalle, 1989; Hulugalle and Ezumah, 1989) It would appear that certain intercrop mixtures may be beneficial in improving soil aeration, reducing soil bulk density, and building up soil organic matter (Lal, 1989; Opara-Nadi et al. 1987).

The importance of intercropping in soil improvement is related to improved soil structure, particularly in the major soils of humid tropics dominated by low activity clays (Juo and Kang, 1987). These soils need additional organic matter to retain nutrients essential for plant growth. Reduced erosion due to continuous vegetative cover provided through intercropping, results in retention of the top soil and associated organic matter (Lal, 1989; Juo and Ezumah, 1990). Increase in soil infiltration, attributed to increased earthworm activity under intercropping, has been reported by Hulugalle and Ezumah (1989). Even in the highly fertile soils of temperate regions, mulching and/or maintenance of vegetative ground cover results in improved crop performance and soil conservation.

The amount of chemicals, soil aeration, and organic matter can be measured. But of what significance are they? Does their importance lie in explaining why and how yield over years is affected? Perhaps only yield should be measured and assessed. An unsolved problem here is how to use these soil measurements (other than yield) more fully. 
Continuous cropping of a mixture for many years will be required in order to measure changes in chemical content, changes in soil structure, and changes in organic matter. The various treatments will be compared against sole crop treatments and a standard intercrop treatment.

\section{DENSITY AND INTIMACY ASPECT}

Mead and Riley (1981), e.g., discuss several topics related to intercropping. Among these is a discussion of the population density per hectare for each of the crops in a mixture, intimacy (closeness of plants of crops to other crops), and spacing and arrangement factors. For sole crops, the problem is rather simple but becomes increasingly complex as the number of crops in a mixture increases. Many of these problems are discussed further in Chapter 9 of Federer (1991). In addition, the ideas of parsimonious experiment design (PED), as described by Federer and Scully (1988), can be used effectively and efficiently to investigate optimal spacing, arrangement, intimacy, and density for each of the crops in a mixture. In formulating PEDs, use has been made of previous ideas like the Nelderfan and Okigbo-circle (see Federer, 1991, for references and description.). Use of PEDs and proposed statistical analyses results in the desired information at considerable savings of time, material, labor, and money. Using PEDs involves changing ideas about setting up an experimental unit and measuring the response from that unit. Functions of responses rather than single responses are used in the statistical analysis.

\section{BIOLOGICAL MODELING ASPECT}

In developing biological theory for a system or procedure like intercropping, different statistical models and procedures from those presented in previous sections are required. It is not sufficient to simply compare cropping systems and mixtures. Knowledge of the biological processes governing why some systems or mixtures perform in the manner they do, is necessary in order to develop methods for producing desired systems and mixtures in a more efficient manner. This situation has precedent in plant hybridization where diallel crossing, top crossing, single crossing, double crossing, and multiple crossing procedures and theory were developed and applied. Research in this area provides ample proof 
of the fact that it is not sufficient just to know that something happens but it is necessary to know why.

Using some of the ideas from the above plus others, biological modeling for intercropping experiments was developed (see Chapters 6 and 7 of Federer, 1991, Federer, 1979, and Federer and Raghavarao, 1987.). For the models proposed, particular treatment designs are necessary. For example, all possible combinations of mixtures of $\mathrm{c}$ crops plus sole crops are necessary for some models such as those described by Federer and Raghavarao (1987). For other models, a subset of the above treatment design suffices. Since the number of treatments can become large, it is necessary to use minimal designs which achieve the desired goal.

In setting up these models, effects such as general mixing ability, bi-specific mixing ability, trispecific mixing ability, etc. are discussed in Federer (1979 and 1991, Chapters 6 and 7). General mixing ability (gma) refers to the ability of a crop or line to mix well with all others in the experiment. A cultivar with a high gma value indicates that it should be a member of mixtures. If a cultivar has a low gma value, this means that it does not mix well with any of the other cultivars in the experiment. When a pair of specific cultivars mixes well with each other but not with other cultivars, we say that this is positive bi-specific mixing ability. When a particular triplet of cultivars is particularly good, we say it has a high tri-specific mixing ability. The individual bi-specifc effects of pairs may not be impressive but the combination of the three is. Statistical designs, models and measures of all these effects are described in the above references.

In plant hybridization, one response from a mixture (cross) of two parents is obtained. In some situations when the items in a crop mixture are not identifiable, there will only be one response for a mixture from an experimental unit. For example, an intermingled mixture of $c$ lines of wheat with similar wheat kernels and plant type would be a case where the contributions from each of the lines was not available and only one response would be possible. If the clines in a mixture were planted in an alternating plant fashion or if the $c$ lines were in $c$ adjacent rows, individual responses could be obtained. When the items in a mixture have quite different plant characteristics, e.g. such as maize 
and beans, the individual crop responses are readily obtained. Statistical models and analysis differs for the two cases, i.e., only a single response for each e.u. or c responses, one for each crop in the mixture. Several models are available for each case (see Federer, 1991).

\section{DISCUSSION}

The comment that available statistical procedures are all that are needed to analyze data from intercropping experiments is shown not to be correct. In analyzing and interpreting results from intercropping experiments, the level of thinking in going from sole crop data to two-crop mixture data goes up in difficulty by an order of magnitude. In going from two-crop mixtures to three-or more-crop mixtures, the level of difficulty goes up by another order of magnitude. The amount of time and effort required for interpretation of results from an intercropping experiment is much greater than for a sole cropping experiment. In analyzing data from an intercropping experiment, the following statement is appropriate, "Expect the unexpected. Be prepared for a surprise over what sole crop mentality would indicate." The complex biological mechanisms involved in community living of plants may be quite different from when plants are living alone as a sole crop. If some of the results observed in past experiments hold up in general, the biologists will need to advance their theory considerably in order to explain the results.

Statistical theory needs considerable extension in order to provide the necessary theory and methods for using such statistics as LER. It is surprising that so little statistical theory is available for ratios of random variables other than the binomial, students $t$, Snedecor's $F$, and the correlation coefficient. Scientists in many fields use ratios of random variables consistently but statistical methods texts do not give the necessary theory and methods for dealing with ratios and sums of ratios of random variables. It would appear that statistical methodology should be extended to provide this theory. Performing a logarithmic transformation will not answer the problem for experimenters. As one sugarbeet breeder said when told that a logarithmic transformation would make his data additive and eliminate interaction, "It is nonsensical to eliminate interaction because that is where all the profit 
is for the sugarbeet growers and refineries! I sell interaction!" Transformation of yield responses from intercropping experiments when using such statistics as LER, RLER, V, VR, C, and RC would not be valid and would be uninterpretable. Uninterpretable measures are of no use to an experimenter even though they might have nice statistical and mathematical properties. The statistics presented in sections 4, 5, and 6 are interpretable and useful for experimenters even if the statistical properties for some of them are unknown.

\section{LITERATURE CITED}

Aina, P.O., R. Lal, and G.S. Taylor. 1977. Soil and crop management in relation to soil erosion in the rainforest of Western Nigeria. In Soil Erosion Prediction and Control. Soil Conservation Society of American, Special Publication No. 21, 75-84.

de Wit, C.T. and J.P. van den Bergh. 1965. Competition among herbage plants. Netherlands Journal of Agricultural Science 13, 212-221.

Ezumah, H.C. and N.R. Hulugalle. 1989. Studies on cassava-based rotation systems in a tropical Alfisol. Agronomy Abstracts, ASA Meeting, Las Vegas, P. 53.

Federer, W.T. 1979. Statistical designs and response models for mixtures of cultivars. Agronomy Journal, 71, 701-706.

Federer, W.T. 1984. Principles of statistical design with special reference to experiment and treatment design. In Statistics: An Appraisal (editors: H.A. David, and H.T. David), The Iowa State University Press, Ames, Iowa, pp. 77-104.

Federer, W.T. 1991. Statistical Design and Analysis for Intercropping Experiments Volume I. (In the process of publication)

Federer, W.T. and B.R. Murty. 1987. Uses, limitations, and requirements of multivariate analyses for intercropping experiments. In Biostatistics (editors: I.B. MacNiell and G.J. Umphrey), D. Reidl Publishing Company, Dordrecht, pp. 269-283.

Federer, W.T. and D. Raghavarao. 1987. Response models and minimal designs for mixtures of $\mathbf{n}$ of 
$m$ items useful for intercropping and other investigations. Biometrika 74, 571-577.

Federer, W.T. and S.J. Schwager. 1982. On the distribution of land equivalent ratios. Bu-777-M in the Technical Report Series of the Biometrics Unit, Cornell University, Ithaca, NY, July

Federer, W.T. and B.T. Scully. 1988. A parsimonious statistical design and breeding procedure for evaluating and selecting desirable characteristics over environments. BU-960-M in the Technical Report Series of the Biometrics Unit, Cornell University, Ithaca, NY, February.

Hulugalle, N.R. and H.C. Ezumah. 1989. Effect of cassava - based cropping system and rotation on soil physical properties of an Alfisol in Southwestern Nigeria. Presented at the 6th International Soil Conservation Conference, Addis Ababa, Ethiopia, November 6-18.

Juo, A.S.R. and H. Ezumah. 1990. Mixed root crop ecosystems in the wetter regions of sub-Saharan Africa. In Food Crop Ecosystems of the World (Editor, C.J. Pearson) Elsiever Scientific Publishers, Amsterdam.

Juo, A.S.R. and B.T. Kang. 1987. Nutrient effects of modification of shifting cultivation in West Africa. In Proc. International Symposium on Nutrient Cycling in Tropical Forest and Savanna Ecosystems Stirling, Scotland, pp. 450-470.

Kass, D.C.L. 1978. Polyculture cropping systems: Review and analysis. NY State College of Agriculture and Life Sciences. Cornell International Agriculture Bulletin 32, 1-69.

Khare, M. and W.T. Federer. 1981. A simple construction procedure for resolvable incomplete block designs for any number of treatments. Biometrical Journal 23(2), 121-132.

Lal, R. 1989. Conservation tillage for sustainable agriculture: Tropics vs. temperate environments. Advances in Agronomy 42, 85-195.

Mead, R. and J. Riley. 1981. A review of statistical ideas relevant to intercropping research (with discussion). Journal of the Royal Statistical Society, Series A, 144, 462-509.

Opara-Nadi, O.A. and R. Lal. 1987 Effects of plant population on soil structure, soil moisture depletion and on yield of cassava (M. esculenta) on an ultisol in Southeastern Nigeria. Soil and Tillage Research 15. 
Patterson, H.D. and E.R. Williams. 1976. A new class of resolvable incomplete block designs. Biometrika 63(1), 83-92.

Pearce, S.C. and B. Gilliver. 1978. The statistical analysis of data from intercropping experiments. Journal of Agricultural Science 91, 625-632.

Pearce, S.C. and B. Gilliver. 1979. Graphical assessment of intercropping methods. Journal of Agricultural Science 93, 51-58.

Willey, R.W. 1979. Intercropping - its importance and research needs. Part 1. Competition and yield advantages. Part 2, Agronomy and research approaches. Field Crop Abs. 32, 1-10 and 7385.

Willey, R.W. and D.S.O. Osiru. 1972. Studies on mixtures of maize and beans (P. vulgaris) with particular reference to plant populations. Journal of Agricultural Science, Cambridge, 79, 517529. 